\title{
Relation of anxiety and pulse rate before tooth exctraction of 6-9 years old children
}

\author{
Sarah Cinthia Richy Artha De Hersa*, Yetty Herdiyati*, Sri Tjahajawati** \\ *Department of Pedodontics Faculty of Dentistry Universitas Padjadjaran \\ **Department of Oral Biology Faculty of Dentistry Universitas Padjadjaran
}

ABSTRACT

Introduction: Anxiety in children during dental treatment is a common problem that affects the success of dental care. Only a few patients come to the dentist without anxiety and it will be far more difficult for dentists to provide satisfactory dental care for tense patients compared to patients who are relaxed and cooperative. The purpose of this study was to analized relationship of the anxiety in children with pulse rate aged 6-9 years old before tooth extraction. Methods: This method of this study was descriptive with a sample of 30 children aged 6-9 years old. The samples collected by using purposive sampling at the first time they would get dental extraction treatment. Measurement used questionnaire with Corah method and measure their pulse before tooth extraction. Results: The result shows in 30 children aged 6-9 years old who first came to the dentist there are $90 \%$ children who have no anxiety, $3,3 \%$ children who have high anxiety, and $6,7 \%$ children who have highest anxiety. The result of statistical analysis of obtained $p$-value is 0,001 less than 0,05 indicating a significant relationship between anxiety and pulse rate of children before tooth extraction. Conclusion: There is strong relationship of the anxiety with the child's pulse before tooth extraction of 6-9 year old children.

Keywords: Anxiety, Corah dental anxiety scale, pulse, tooth extraction.

\section{INTRODUCTION}

The World Health Organization (WHO) defines health as a state of well-being, physical, mental, social, and not just free from disease or weakness. Healthy according to the Law of Health of the Republic of Indonesia Number 23 of 1992, which includes elements of productive life both social and economic. ${ }^{1}$

Health is influenced by a person's habits and lifestyle. A person can maintain his health and prevent disease by checking his health to the hospital regularly. However, most people only visit the hospital when the condition of the body decreases. Even some of them stalling hospital visits, one of them because of anxiety that arises. ${ }^{2}$ Some people feel anxious to check their health to the hospital, especially to the dentist. Only a few patients come to the dentist without anxiety and it will be far more difficult for dentists to provide satisfactory dental care for tense patients compared to patients who are relaxed and cooperative. $^{2}$

Anxiety will affect the success or failure of the dentist in treating patients. The establishment of a good professional relationship with the patient is needed to be able to create a situation so that the patient is in a relaxed condition and 
the dentist can work freely. A good relationship between the doctor and the patient can also raise awareness for the patient to have a check on the health of his teeth and mouth, without having to wait for the onset of tooth pain or severe conditions that require surgery so that it disrupts the life of the patient. ${ }^{2}$

New patients are generally very anxious and afraid of what they will experience in the dentist's office. One of these fears is caused by the attitude of the dentist who lacks an explanation of the treatment measures so that often makes patients feel anxious. ${ }^{2}$ Anxiety can be reviewed from cognitive, behavioural, and physical aspects. Based on the cognitive aspect, the characteristics of anxiety are worrying about something, the belief that something terrible will happen immediately without a clear explanation, thinking about the same annoying things over and over again, and difficulty concentrating and focusing the mind. Based on aspects of behaviour, the characteristics of anxiety are avoidance and dependence behaviour. Based on physical aspects, the characteristics of anxiety are blushing, hands or limbs trembling, sweating a lot, heart beating fast. ${ }^{3}$

Early childhood aged 6-9 years can adapt to new environments, able to take the desired action even though sometimes it shows an increase in anxiety. ${ }^{4}$ Children begin to be able to overcome the anxiety about dental care that will be received by listening to the explanation from the dentist and expressing pain with body movements. Each individual has varying anxiety. ${ }^{5}$ At the age of 6-9 years is a period of mixed teeth characterized by the presence of deciduous teeth and permanent teeth simultaneously so that many teeth extraction is done in children aged. ${ }^{6}$

Tooth extraction can cause anxiety in children which is a combination of patient factors and dentist factors themselves. Patient factors such as personal assumptions, the patient's ignorance of the treatment performed by dentists, and the existence of personal experience. One of the dentist factors is attitude and type of treatment, such as injection prior to the extraction before the patient's eyes. This results in patients feeling uncomfortable and reluctant to seek treatment problem teeth. $^{7}$

Measurement of anxiety can be done in various ways. Assessment based on the patient's subjective reaction especially to dental treatment can use a questionnaire with the Corah Dental Anxiety Scale method. This questionnaire is in the form of multiple-choice questions with the assessment score criteria for each question. If the total score of the questions is more than 13 , children with high anxiety and greater than 15 are children with very high anxiety. ${ }^{8}$ An objective measurement of anxiety is done by measuring the pulse. The average pulse rate of a child is $80-100$ times per minute. But it can be faster if someone is anxious or afraid. ${ }^{9}$ The purpose of this study was the purpose of this study was to analized relationship of the anxiety in children aged 6-9 years old with extraction teeth.

\section{METHODS}

This research is descriptive. According to Sugiyono ${ }^{10}$, descriptive research is a research method that seeks to describe and interpret objects according to what they are. The population in this study were children who came for treatment at the Dental and Oral Hospital of the Faculty of Dentistry, Padjadjaran University in November-December 2011.

The sample in this study was children aged 6-9 years who went to the Dental and Mouth Hospital of the Faculty of Dentistry, Padjadjaran University and for the first time they would get dental extraction treatment. The sampling method is purposive sampling based on individual considerations or the consideration of researchers.

Population criteria are determined by several considerations, namely, primary school age children, 6-9 years old, available to participate in the study, have no mental retardation, first visit to the dentist, and the first time you will receive treatment tooth extraction . obtained data on anxiety in children aged 6-9 years through the Corah method questionnaire and measure the child's pulse before the tooth extraction is performed.

\section{RESULTS}

The results of this study were obtained from a sample of 30 children aged 6-9 years who were the first to visit a dentist and would do a tooth extraction at the Dental and Oral Hospital of the 
Faculty of Dentistry, Padjadjaran University during November-December 2011. Tabel 1 below shows an overview-age-characteristics of 30 children who have had tooth extraction at the Dental and Oral Hospital of the Faculty of Dentistry, Padjadjaran University.

Based on table 1, it can be seen that the most children who extracted teeth at the Dental and Oral Hospital of the Faculty of Dentistry, Padjadjaran University aged 6 and 7 years, namely 9 people each or as much as $30 \%$ of the total 30 children who were sampled. On the contrary, the least respondents were 8-year-old children, namely only 5 people or $16.7 \%$ of the total 30 children who became the study sample.

Anxiety level of children aged 6-9 years in tooth extraction is measured in 2 ways, first by giving a questionnaire to respondents before tooth extraction. Second, by measuring the child's pulse before the tooth extraction is done. The following table 2 shows the measured pulse rate in anxious children based on the number of questionnaire scores before tooth extraction.

The relationship between anxiety and pulse is measured using product moment correlation, which is by correlating the anxiety score results of the questionnaire with

Table 1. Distribution of respondents by age

\begin{tabular}{crc}
\hline Age & Total & Percentage \\
\hline 6 years & 9 & $30 \%$ \\
7 years & 9 & $30 \%$ \\
8 years & 5 & $16.7 \%$ \\
9 years & 7 & $23.3 \%$ \\
\hline Total & 30 & $100 \%$ \\
\hline
\end{tabular}

Table 2. Measuring pulse value of anxiety children based on the total questionnaire score before tooth extraction

\begin{tabular}{cccc}
\hline No & Age & Number of questionnaire scores & Pulse \\
\hline 1 & 8 years & 15 & 103 \\
2 & 6 years & 14 & 110 \\
3 & 6 years & 15 & 120 \\
\hline
\end{tabular}

Table 3. Test the relationship of anxiety with pulse

\begin{tabular}{cc}
\hline Statistics & Score \\
\hline Correlation coefficient & 0.566 \\
$p$-value & .001 \\
Relationship Criteria & Strong enough \\
\hline
\end{tabular}

the pulse. From the results of processing using a statistical program the correlation coefficient obtained between the anxiety score with the pulse rate as shown in Table 3 .

Table 3 shows the correlation coefficient between anxiety and the child's pulse before tooth extraction is 0.566 in the positive direction. This means that children who have higher anxiety tend to have faster pulses. Then the $p$-value of 0.001 is smaller than 0.05 , indicating there is a significant relationship between anxiety and the child's pulse before tooth extraction. ${ }^{11}$

\section{DISCUSSION}

The results of the study based on the questionnaire showed that of 30 children there was 1 child or $3.3 \%$ who had a high level of anxiety and $6.7 \%$ with very high anxiety. This result is based on the provisions of the Corah Dental Anxiety Scale questionnaire which states that the total score of more than 13 is a child who has high anxiety and the total score is greater than 15 is a child with very high anxiety. In children who have a high level of anxiety have results that are comparable to a fast pulse.

Children who first visited the dentist for treatment usually experience more anxiety. ${ }^{12}$ According to the results of the study, children (10\%) feel anxious because they have concerns about what they will face when they go to the dentist and imagine something scary because they have no prior experience with the dentist. But in some others, children become anxious because they get a greeting and see a friendly attitude from the dentist in providing explanations and treatments so as to make the child feel comfortable.

The state of the dentist's waiting room is also a factor influencing a child's anxiety. ${ }^{13}$ Children's answers to questions about feelings while waiting in the waiting room before getting treatment most of the children feel calm. According to researcher interviews, children feel calm when in the waiting room because children can play and watch television. Another reason that makes children feel calm is because they are waiting to be accompanied by a parent or relative who takes the child to the doctor tooth.

Children who feel anxious can act unpleasant 
while in the care chair, are uncooperative, and sit uneasy. ${ }^{14}$ The results showed that most children felt anxious when performing dental care, this result was supported by children's answers to questions about children's feelings when sitting in a dental chair and waiting for dental care. Children respond that they feel anxiety. Based on the researcher's interview, the child felt anxious because he was not familiar with the dental chair and examination environment.

Child's reaction when he sees the tool used by a dentist can affect the level of anxiety of children..$^{13}$ In this study, the child's response to seeing a dental treatment instrument can be shown by the child's response to the question about the child's feelings when the dentist took the dental treatment instrument and the tooth will be revoked. The child feels tense seeing the dental care instrument and knows his teeth will be revoked. According to researcher interviews, children feel tense when looking at instruments because they are not accustomed to seeing instruments and are reluctant to go to the dentist for fear of feeling pain when seeing sharp objects enter the mouth and think that all dentists' actions are painful.

Children aged 6-9 years old are in elementary school level. Primary school age is the most effective age in receiving knowledge and dental health care. The emergence of anxiety in children is the result of the child's perception of dental care through experience, listening to stories and reading books. Anxiety often causes children to be negative towards dental care so it refuses to accept dental care.

According to Widodo $^{15}$, anxiety in children can cause an increase in heart rate and breathing. ${ }^{16}$ These results are consistent with the results of pulse measurements performed on children who were assessed anxiously based on a questionnaire (Table 2). A similar study was also carried out by Gillum et al in which approximately $1 \%$ of 10,031 children experienced an increase in blood pressure at the first visit to dentist.

The results of the analysis of anxiety measurements in children aged 6-9 years before tooth extraction at the Dental and Mouth Hospital of the Faculty of Dentistry, Padjadjaran University through questionnaires and pulse checks have a significant correlation value between anxiety and high pulse of the child before the extraction of teeth (Table 3). Based on the results of research on children aged 6-9 years who first came to the Dental and Oral Hospital of the Faculty of Dentistry, Padjadjaran University to get dental extractions it was summarized that there were 27 children who were not anxious, 1 child who had a high level of anxiety and 2 children with very high anxiety accompanied by increased pulse before tooth extraction.

\section{CONCLUSION}

There is strong relationship of the anxiety with the child's pulse before tooth extraction of 6-9 year old children.

\section{REFERENCES}

1. Effendi O. Communication theory and practice. Bandung: Teen Rosdakarya. 2009. p. 45-7.

2. Eccles J. How the self controls its brain. Berlin: Springer-Verlag. 1994. p. 33, 176.

3. Jeffrey S. Abnormal psychology. Jakarta: Erlangga Publisher. 2005. p. 163-9.

4. Cameron, Widmer. Handbook of pediatric dentistry. Philadelphia: Mosby Elsevier. 1994. p. 10-11.

5. Finn CT, Smoller JW. The genetics of panic disorder. Curr Psychiatry Rep 2001;3:131-7.

6. Ash M. Dental anatomy, physiology, and occlusion. Philadelphia: WB. Saunders Co. 1993. p. 29-30.

7. Sri H. Tackling Fear Children in Dental Care. J Dentis, UI. 2003;10:35-40.

8. Doerr PA, Lang WP, Nyquist LV, Ronis DL. Factors associated with dental anxiety.J Am Dent Assoc. 1998 Aug;129(8):1111-9.

9. Guyton A. Medical physiolog. Jakarta: EGC. 1997. p. 133-4.

10. Sugiyono. Statistics for Research. Bandung: CV. Alfabeta. 2007. p. 219.

11. Lemuel A. Statistical Reasoning in Medicine. $2^{\text {th }}$ ed. USA: Springer. 2006. p. 51.

12. Jay. Your child's first dental visit. Available from:http: / /www.drjay.com/1stvisit.com. [Cited 9 Jan 2011). 2007.

13. Corah NL,Gale EN, Illig SJ. Assessment of a dental anxiety scale. JADA, 1987;97:816-9. 
14. Ruslan G. Fear and stress in patients during dental care. PDGI J. 1991;40(2):30-3.

15. Widodo S. Overcoming anxiety in children. Available from: http: //www.googlesearch/ anxiety.com. [Cited 1 Aug 2011]. 2007.

16. Jeune, Gordy. Evaluation of blood pressure in children and adolescent: A review. J Clin Ped Dent. 1999;23:169-72. 